NBER WORKING PAPER SERIES

\title{
THE TWO-PART INSTRUMENT IN A SECOND-BEST WORLD
}

\author{
Don Fullerton \\ Ann Wolverton \\ Working Paper 10140 \\ http://www.nber.org/papers/w10140 \\ NATIONAL BUREAU OF ECONOMIC RESEARCH \\ 1050 Massachusetts Avenue \\ Cambridge, MA 02138 \\ December 2003
}

We are grateful for suggestions from Allen Blackman, Firouz Gahvari, Robert Mohr, Ian Parry, Agnar Sandmo, Ronnie Schöb, and Hilary Sigman and for financial assistance from the Environmental Protection Agency (R824740-01-0) and the National Science Foundation (SBR-9811324). This paper is part of the NBER's research program in Public Economics. Any opinions expressed are those of the authors and not those of the EPA, the NSF, or the National Bureau of Economic Research.

(C)2003 by Don Fullerton and Ann Wolverton. All rights reserved. Short sections of text, not to exceed two paragraphs, may be quoted without explicit permission provided that full credit, including (C notice, is given to the source. 
The Two-Part Instrument in a Second-Best World

Don Fullerton and Ann Wolverton

NBER Working Paper No. 10140

December 2003

JEL No. H2, Q2

\section{ABSTRACT}

The standard theory that the first-best tax on pollution is equal to marginal environmental damages has been extended in two directions. First, many polluting activities are difficult to tax because they are not market transactions, and so recent papers have shown that the same effects can be achieved by use of a two-part instrument - a tax on one market transaction such as output or income and a subsidy to a different market transaction that is a clean alternative to pollution. It is a generalization of a deposit-refund system. Second, a different literature concerns the second-best optimal pollution tax in the presence of other tax distortions. Here, we combine the two extensions by looking at the second-best two-part instrument (2PI). When government needs revenue, is the deposit larger and the rebate smaller? We find explicit solutions for each tax and subsidy in a general equilibrium model with other tax distortions, and we compare these to the rates in a first-best model. The taxsubsidy combination is explained in terms of a tax effect, an environmental effect, and a revenue effect. The model allows for flexible interpretation, to show various applications of the 2PI. We also discuss important caveats, cases where the 2PI may not be appropriate.

Don Fullerton

The University of Texas at Austin

Department of Economics

1 University Station C3100

Austin, TX 78712

and NBER

dfullert@eco.utexas.edu

Ann Wolverton

U.S. Environmental Protection Agency

Washington, DC 20460

wolverton.ann@epamail.epa.gov 
Pigou (1920) first suggested a direct tax on waste, at a rate equal to marginal external damages, as an efficient method of controlling pollution. It raises the price of the dirty input to induce substitution in production, and it raises the price of the final product to reduce demand. A Pigovian tax may be feasible for pollutants such as sulfur dioxide emitted by large electric utilities because of the availability of continuous emissions monitoring (CEM) equipment. Carbon emissions may also be taxed effectively because accurate estimates can be based on the carbon content of fossil fuels purchased in the market. As a practical matter, however, other direct taxes on waste are rare. Many types of pollution are difficult to monitor; CEM equipment often is too costly for smaller firms or individual consumers, and other reliable emission estimation techniques may not be available. Even when measurement of pollution is possible, enforcement of the tax may not be feasible. For instance, a tax on toxic waste may provide a powerful incentive to reduce as much waste as possible, but it may also induce illegal dumping or burning. ${ }^{1}$

Fortunately, alternative incentive-based methods are available that retain many of the properties of a direct tax while minimizing the need for monitoring and enforcement. An output tax can raise the price to the consumer, which reduces production and consumption of the good. Eskeland and Devarajan (1996) call this a presumptive tax, because it presumes that the production process pollutes or that the consumption good eventually will become waste. In addition, a subsidy can be provided for cleaner technology used in production, or for recycling the final good. This subsidy to clean inputs makes dirty inputs relatively more expensive, causing substitution away from the dirty input. Fullerton and Wolverton (1999) call this combination a two-part instrument, and they find a first-best closed-form solution that exactly matches the incentive effects of a direct tax on pollution or waste. ${ }^{2}$

A practical example is a deposit-refund system on items such as glass bottles or aluminum cans. The two-part instrument (2PI) is a generalization of a depositrefund system, however, because it can be used to address other types of pollution. The tax and subsidy do not have to apply at the same rate, to the same commodity, or even to the same economic agent. The point is to avoid the enforceability or measurement problems of a tax on pollution by applying the tax to observable market transactions such as the purchase of an output by the consumer and simultaneously to subsidize other market transactions such as the purchase of clean inputs by the polluting firm.

In this paper, we examine the two-part instrument when the government has a revenue-raising requirement and cannot use lump-sum taxes. Because of distortionary taxes, the first-best solution is no longer valid. We find that the presumptive tax on output now consists of an environmental component that helps correct for the negative externality and a revenue-raising component. The subsidy also is adjusted, to account for the cost of raising public funds.

\footnotetext{
${ }^{1}$ Research by Russell, et al (1986), Harrington (1988), and Lear (1998) indicates that government monitoring and enforcement activity is quite low. For instance, EPA fined only 200 firms in 1995. Estimates of firm compliance vary widely: Magat and Viscusi (1990) find that, despite low enforcement activity, pulp and paper mills complied with environmental regulations about 75 percent of the time between 1982 and 1985. The U.S. General Accounting Office (1979) finds that only 200 of 921 polluters thought to be in compliance actually were (Cohen, 1999).

${ }^{2}$ Eskeland (1994) and Palmer and Walls (1997) also discuss combinations of instruments, and Walls and Palmer (2001) also provide closed-form solutions for the first-best two-part instrument.
} 
To raise revenue, one might think that the government would optimally increase the presumptive tax rate (or "deposit") above its first-best level and reduce the environmental subsidy ("refund") below its first-best level. Our results below show that the validity of this logic depends on one's interpretation of "the deposit." If the deposit is the entire presumptive tax, then indeed the deposit is larger because of the need for revenue. If the "deposit" is defined solely as the environmental term of the presumptive tax, then the deposit is smaller than in the first-best case.

Other recent papers develop general equilibrium models of economies with a dirty good, a clean good, and a tax on labor supply [see e.g. Bovenberg and de Mooij (1994), Parry (1995), and Bovenberg and Goulder (1996)]. Their principle objective is to investigate whether the optimal tax on the dirty good is higher or lower in the face of pre-existing distortions in the economy. When they assume separability of leisure in the utility function, they find that a tax on the dirty good tends to exacerbate pre-existing distortions from the labor tax. Thus, the second-best tax on the dirty good is below the level of the first-best or Pigovian tax rate. ${ }^{3}$ Schöb (1997) and Fullerton (1997) build similar general equilibrium models to analyze several different possible tax combinations, and they show that the tax on the dirty good may be above or below the first-best rate, depending on the selected normalization. Any one tax rate can be set to zero. Bovenberg and de Mooij (1994), Parry (1995), and Bovenberg and Goulder (1996) all set the tax on the clean good to zero, which leads to the result that the labor tax raises revenue and the tax on the dirty good falls below marginal external damages (MED). Schöb and Fullerton set the labor tax to zero and show how the tax on the dirty good exceeds MED.

None of those analyses set the tax on the dirty good to zero, and yet the dirty good is likely to be the one most difficult to tax. Often the dirty input is pollution, an input that is not purchased in a market transaction with an invoice to verify the tax base. The effluent may be difficult or impossible to measure, and even measurable pollutants can be released without reporting ("midnight dumping"). Here, even with no tax on pollution, we demonstrate how policymakers may correct for the externality and raise revenue in an optimal way.

Earlier papers also discuss imperfect taxation of externalities. Some consider the case where the MED differs among polluters, and differential taxation is not available. ${ }^{4}$ In that second-best case, taxes or subsidies on other goods may help. That problem does not arise here, however, as we are only concerned with the case where all polluters cause the same marginal damage. Our paper is more similar to the case studied by Sandmo (1976), where a tax can only be applied to the purchase of a potentially dirty good and not to the dirty use of it. Again he finds that taxes or subsidies on other goods may help. We effectively extend Sandmo's model in two directions. First, we note that the first-best can be re-achieved in his model by adding a subsidy to the clean use of that good. Second, we add labor taxes.

We build a general equilibrium model with distorting labor taxes similar to those of Schöb (1997) and others mentioned above, and we use it to solve explicitly for the second-best two-part instrument. We show results both in the general case and in a special case with separability in utility. Deriving an explicit solution allows for direct comparison to results from a first-best model. In addition, the model allows for a flexible interpretation of results. Several distinct interpretations will be

\footnotetext{
${ }^{3}$ For a similar model with more general preferences, see Cremer, Ghavari, and Ladoux (2001).

${ }^{4}$ See Diamond (1973), Green and Sheshinski (1976), and Balcer (1980).
} 
discussed to illustrate the potential applicability of such a policy instrument to various pollution problems. Several important caveats regarding implementation of the 2PI are also discussed. These include: (1) difficulty enforcing the output tax itself; (2) disaggregation and the potential need for a large number of instruments; (3) firm or consumer heterogeneity and the imperfection of uniform rates; (4) nonseparability of environmental quality; (5) geographic or temporal variation in damages; (6) different types of subsidies; (7) changes in monitoring technology that may allow policy shifts away from the $2 \mathrm{PI}$ and toward direct taxation; and (8) interjurisdictional trade.

The paper is organized as follows. First, as a basis for comparison, we review results in a simple first-best general equilibrium model with no revenue requirement. Second, we discuss several possible interpretations and applications. Third, we construct a model with a revenue-raising requirement and solve it to obtain explicit expressions for the tax and subsidy. Fourth, we discuss a number of important caveats about policy implementation of the two-part instrument.

\section{The First-Best Model}

We begin with a simple warm-up exercise designed to introduce the notation, to illustrate the two-part instrument, and to serve as a basis of comparison for our later derivations in a second-best model. In the tradition of Baumol and Oates (1988), Fullerton and Wolverton (1999) build a first-best general equilibrium model where the dirty good is produced using labor and emissions, and they show that the optimal tax on emissions can be replaced by a 2PI with a tax on the dirty output and a subsidy to labor used in that industry. In that model, the "deposit" and the "refund" are not at the same rate. They are not even on the same good. We refer later to that case. For direct comparison to second-best results below, however, we now demonstrate the logic of the 2PI in a far simpler model with only one input (where the negative externality is directly associated with the amount of one output). The economy is closed, with only one jurisdiction. We also assume perfect competition, perfect information, no transactions costs, and no other distortions.

The society consists of $n$ identical households. Each household owns one unit of a resource, interpreted as a fixed amount of labor, land, capital, or any other resource that can be sold in the market or used at home. The household may exchange some of this resource for income and then purchase a clean good $c$ and a dirty good $d$. The household may also keep some of the resource to produce a household good $h$, interpreted either as leisure or as household production. We assume linear production, and we define units such that the marginal rate of transformation is equal to 1 . Thus, the resource constraint is simply: $h+c+d=1$. Utility of the household, $u$, depends positively on each of these three goods and negatively on the total amount of the dirty good, $D=n d$. Throughout the paper, lower case letters denote individual household amounts, while upper case letters denote aggregates for the society. ${ }^{5}$

The social planner maximizes utility subject to the resource constraint, recognizing the effect of each household's consumption of $d$ on the total amount, $D$. Thus, the optimization problem is:

\footnotetext{
${ }^{5} \mathrm{We}$ also assume that utility is twice continuously differentiable and strictly quasi-concave.
} 


$$
\max u(c, d, h, n d)+\gamma(1-h-c-d]
$$

with respect to $c, d$, and $h$. This yields the first order conditions:

$$
\begin{aligned}
& u_{c}=\gamma \\
& u_{d}+n u_{D}=\gamma \\
& u_{h}=\gamma
\end{aligned}
$$

where a subscript denotes a partial derivative, and $\gamma$ is the social marginal value of the resource. These first order conditions state that the social marginal utility from an additional unit of $c, d$ or $h$ equals the social marginal cost.

In the private market with perfect competition, the individual household maximizes utility subject to its budget constraint:

$$
\max u(c, d, h, D)+\lambda\left[(1-h)\left(1-t_{r}\right)-c\left(1+t_{c}\right)-d\left(1+t_{d}\right)\right]
$$

where prices are normalized to one, $t_{c}$ is the tax per unit of $c, t_{d}$ is the tax per unit of $d$, and $t_{r}$ is the tax per unit of resources supplied in the market, $(1-h)$. The household treats $D$ as fixed when it maximizes utility with respect to $c, d$ and $h$. The first order conditions from the individual household's problem are:

$$
\begin{aligned}
& u_{c}=\lambda\left(1+t_{c}\right) \\
& u_{d}=\lambda\left(1+t_{d}\right) \\
& u_{h}=\lambda\left(1-t_{r}\right)
\end{aligned}
$$

Optimal tax rate combinations are found when the market (equations $4 \mathrm{a}-4 \mathrm{c}$ ) is induced to match the social optimum (equations $2 \mathrm{a}-2 \mathrm{c}$ ).

First, we examine the case where the dirty good is taxed directly (so $\left.t_{c}=t_{r}=0\right)$. From (2a) and (4a), we then find that $\lambda=\gamma$. Using this relationship in combination with $(2 \mathrm{~b})$ and $(4 \mathrm{~b})$ reveals that the optimal tax on $d$ is:

$$
t_{d}=\frac{-n u_{D}}{\lambda}
$$

This result is the Pigovian tax derived in Baumol and Oates (1988): the total, for all $n$ households, of the marginal disutility from another unit of $d$, converted into dollars when divided by the marginal utility of income. It is marginal external damage (MED).

Suppose, however, that $t_{d}$ cannot be used as a policy instrument, either because it is difficult to enforce or because $d$ is hard to measure. ${ }^{6}$ With $t_{d}$ set to zero, we can instead use $t_{c}$ and $t_{r}$. With a non-zero tax on $c$, however, $\gamma$ no longer equals $\lambda$. Using (2a) and (4a), we find that $\gamma=\lambda\left(1+t_{c}\right)$. Also, from (2c) and (4c), we have $\gamma=\lambda\left(1-t_{r}\right)$. Thus, in this case, $t_{c}=-t_{r}$. Next, with $t_{d}=0$, (4b) states that $\lambda=$ $u_{d}$. If we substitute $\gamma=\lambda\left(1-t_{r}\right)$ into (2b) and solve for $t_{r}$, we have:

\footnotetext{
${ }^{6}$ It may appear that purchase of the dirty good could be measured directly or by taking income minus purchase of the clean good. In spite of this, we use this simple model for its transparency, for comparison to second-best results below, and to demonstrate what rates could replace a direct tax $t_{d}$. We then discuss more complex examples where $d$ is not so observable.
} 


$$
\begin{aligned}
& t_{r}=\frac{-n u_{D}}{\lambda} \\
& t_{c}=\frac{n u_{D}}{\lambda}
\end{aligned}
$$

Given that $\lambda>0$ and $u_{D}<0, t_{r}$ is a positive tax rate. This tax applies to all earnings. The subsidy $t_{c}<0$ is a rebate on all spending except spending on the dirty good. These two instruments together induce a market result that satisfies the social optimum, just as the Pigovian tax does.

Thus, even a very simple model can be used to demonstrate the equivalence of the two-part instrument with the standard Pigovian tax. This tax-subsidy combination differs from the standard deposit-refund system in that the tax applies to all labor and capital income while the subsidy is on an entirely different commodity.

We further consider the general case below, but a special case is where utility is separable and homogeneous in $c$ and $d$. Thus, the utility function can be written as $u(q(c, d), h, D, G)$. This special case has no effect on the results above, but it is useful for discussion below where sub-utility $q(c, d)$ is interpreted as a homeproduced good (or even a market good) produced using $c$ and $d$ as inputs. In this special case, where all income from sale of resources is used to purchase the two goods $c$ and $d$, the tax on sale of resources $\left(t_{r}\right)$ is equivalent to a tax on good $q$ $\left(t_{q}\right)$. In this case, the 2PI can be described as a tax on output $q$ with subsidy to clean input $c$ (as in the other model of Fullerton and Wolverton, 1999).

Finally, consider a case with many goods. If utility depends on one dirty good and many clean goods $c_{i}(i=1, \ldots, N)$, then a first-best 2PI needs to tax income and subsidize all clean goods at the same rate. ${ }^{7}$ Or, suppose utility depends on many goods $q_{i}$, some of which have clean and dirty inputs where $q_{i}=q_{i}\left(c_{i}, d_{i}\right)$. Then the model can be used to show that a tax on any one dirty input $d_{i}$ can be replaced with a two-part instrument that taxes output $q_{i}$ and subsidizes the clean input $c_{i}$.

\section{Interpretations and Applications}

With the simple results above, we are now able to discuss several possible interpretations and applications of the two-part instrument. All of this discussion applies equally to the first-best model above and the second-best model below. In particular, we can interpret the variables $c$ and $d$ in four different ways. For these interpretations, we use the special case where those two goods are separable and homogeneous, so $u=u(q(c, d), h, D, G)$, but we return to the general case later. ${ }^{8}$ Caveats related to the use of the two-part instrument for pollution control, applicable in the context of both models, will be discussed in detail in Section IV.

The first interpretation is the usual interpretation in the optimal tax literature where $c$ and $d$ are commodities, $q(c, d)$ is a sub-utility function, and $d$ generates fixed pollution per unit (either from production or from consumption of the good). If

\footnotetext{
${ }^{7}$ The derivation looks much like equations (1)-(6), but with a set of clean goods $c_{i}$ and tax rates $t_{c i}$. The result is that all $t_{c i}$ equal the same $n u_{D} / \lambda$ as in equation (6b).

${ }^{8}$ These assumptions are typical in the literature about second-best taxes on pollution, following Bovenberg and de Mooij (1994), Schöb (1997), and many others. Exceptions include Parry (1995), Ballard, Goddeeris and Kim (2000), Cremer and Gahvari (2001), Cremer et al (2001), West and Williams (2002), and Kim (2002). These exceptions look at taxes on a polluting good. Below, we derive a second-best tax-subsidy combination with no tax on the polluting good.
} 
$q$ is commuting, for example, then a policy maker concerned with congestion could tax driving $d$, or instead impose a 2PI with a tax per inner-city worker and subsidy to public transportation - effectively leaving a tax on those who drive. Likewise, a city wishing to encourage brownfield redevelopment could tax all development via property tax on improvements and offer a subsidy specifically for development of brownfield sites. As these examples make clear, policy makers already employ the 2PI idea in various forms. In some cases, the "deposit" may be folded into the income tax and not explicitly observed by the consumer, while the rebate is returned in the form of a lower sales tax on purchase of the clean good or via income tax deduction with receipts that prove purchase.

A second interpretation is that $c$ and $d$ are clean and dirty characteristics of a commodity $q$. For example, let $q$ be a household vehicle, where $c$ is a characteristic that reduces emissions (pollution control equipment) and $d$ is a characteristic that increases emissions (vehicle age, size, or poor maintenance). For the moment, suppose mileage is fixed. A direct tax on vehicle emissions involves measurement and monitoring, which may be costly or unenforceable. Instead, using this model, the government may tax the ownership of any vehicle and then subsidize the consumer's installation and maintenance of pollution control equipment. ${ }^{9}$

A third interpretation of the model is that $q(c, d)$ represents the household's or firm's technology of disposal for commodity $q$, where $c$ is a clean form of disposal and $d$ is a dirty disposal alternative such as dumping. The consumer chooses amounts of $c$ and $d$ consistent with any given $q$. A "bottle bill" fits within this interpretation, where $q$ is the quantity of bottled drinks, $c$ is clean disposal through recycling, and $d$ is litter. Because it is generally not practical to monitor or prevent litter or dumping, a tax on $d$ is not feasible. The two-part instrument would then appear as a tax on purchases of $q$ and a subsidy to household recycling $c$. This combination effectively taxes the use of $d$ without actually applying a direct tax to this disposal alternative. Similar deposit-refund systems have applied to used tires, motor oil, and lead-acid batteries. Another potential application would be to mercury used in dental amalgams (also known as silver fillings). If not retained and recycled, this mercury could end up in the municipal wastewater system. These examples all involve households or firms that are both numerous and small, unlike large firms such as electric utilities that can be monitored by CEM technology. ${ }^{10}$

A fourth interpretation is that $q(c, d)$ is actually a firm's constant-returns-toscale production function that has been substituted into the household's utility function. Thus, inputs to the production of $q$ consist of a clean input $c$ and a dirty input $d$. This example is particularly relevant when we think of the dirty input as emissions. The firm may pay some private cost related to these emissions, but it does not face the external cost. In the event that emissions cannot be measured,

\footnotetext{
${ }^{9}$ For a more detailed analysis of the application of the 2PI to vehicle emissions with variable mileage (but without other distorting taxes), see Fullerton and West (2002). Specifically, they discuss the circumstances in which the direct tax on emissions can be replaced by the combination of a tax on gasoline, a tax on engine size, and a subsidy to pollution control equipment.

${ }^{10}$ Another example is the use of performance bonds to encourage the clean up of mines upon closing. All companies pay an up-front deposit assuming that the mining process will result in a certain amount of hazardous waste. A proportion of this amount is then refunded to the company depending on the amount of cleanup required. If the mining company properly disposes of all hazardous waste at the site, then it qualifies for a refund of the full deposit.
} 
policy makers still can induce the firm to emit an optimal amount of $d$ by taxing the household's purchase of $q$ (or income from $r$ ) and giving a subsidy to the firm for using more of the clean input (e.g. pollution abatement technology). ${ }^{11}$ A final example is the use of the 2PI to control non-point nutrient run-off from agriculture, which is difficult to monitor but causes significant contamination of ground and surface waters as well as eutrophication. A 2PI can tax all purchases of fertilizers and pesticides and provide a subsidy to farmers who demonstrate run-off mitigation (e.g. buffers between fields and streams such as unused land, berm, or tree-line). It leaves a tax only on fertilizer not protected by a buffer.

The two-part instrument is not a panacea (see Section IV on caveats). It needs to be applied carefully, but it has advantages that make it worth exploring in various contexts - including the case where government needs revenue and cannot use lump sum taxes.

\section{The Second-Best Model}

Now, to modify the model in Section I, suppose that the government provides some fixed amount of public good $G$ and cannot use lump sum taxes to finance it. We also assume separability of private goods from public goods including environmental quality, so $u=u(H(\mathrm{c}, d, h), D, G)$. We consider this "general" case and the special case where leisure is separable. Households maximize utility with respect to $c, d$, and $h$ but takes $D$ and $G$ as given. The household budget constraint is:

$$
\left(1+t_{c}\right) c+\left(1+t_{d}\right) d=\left(1-t_{r}\right)(1-h)
$$

This maximization yields indirect utility $v\left(t_{r}, t_{c}, t_{d}, \mathrm{D}, \mathrm{G}\right)$. Again assume that $r=(1-h)$ is the only input to production, so the economy-wide resource constraint is:

$$
G+n c+n d=n r
$$

Also, assume that the government must balance its budget:

$$
G=t_{c}(n c)+t_{d}(n d)+t_{r}(n r)
$$

To derive optimal tax rates, we assume that the government's goal is to maximize social welfare, or equivalently, the utility of a representative household. Because each household maximizes its own utility in the marketplace, the government can maximize indirect utility subject to its budget. ${ }^{12}$

With $t_{d}$ constrained to zero, the government sets $t_{c}$ and $t_{r}$ to maximize:

$$
v\left(t_{c}, t_{r}, G, D\right)+\mu\left(t_{c} c+t_{r} r-\frac{G}{n}\right)
$$

\footnotetext{
${ }^{11}$ Despite obvious political difficulties with taxing the household while subsidizing the polluting firm, this interpretation illustrates that the tax and subsidy do not have to apply to the same economic agent. Such difficulties may be avoided by taxing the firm's output instead of household income.

${ }^{12}$ This framework and method are similar to those of Sandmo (1975), Auerbach (1985), Schöb (1997), and countless other papers in the optimal tax literature.
} 
where $\mu$ is the marginal utility cost of public spending. First order conditions are:

$$
\begin{aligned}
& \frac{\partial v}{\partial t_{c}}+n \frac{\partial v}{\partial D} \cdot \frac{\partial d}{\partial t_{c}}+\mu\left(\frac{\partial c}{\partial t_{c}} t_{c}+\frac{\partial r}{\partial t_{c}} t_{r}+c\right)=0 \\
& \frac{\partial v}{\partial t_{r}}+n \frac{\partial v}{\partial D} \cdot \frac{\partial d}{\partial t_{r}}+\mu\left(\frac{\partial c}{\partial t_{r}} t_{c}+\frac{\partial r}{\partial t_{r}} t_{r}+r\right)=0 .
\end{aligned}
$$

These conditions tell us that the marginal utility from one more unit of tax is equal to its marginal cost. Using Roy's identity, ${ }^{13}$ we rewrite (11a) and (11b) as:

$$
\begin{aligned}
& (\mu-\lambda)_{c}+n \frac{\partial v}{\partial D} \cdot \frac{\partial d}{\partial t_{c}}+\mu\left(\frac{\partial c}{\partial t_{c}} t_{c}+\frac{\partial r}{\partial t_{r}} t_{r}\right)=0 \\
& (\mu-\lambda) r+n \frac{\partial v}{\partial D} \cdot \frac{\partial d}{\partial t_{r}}+\mu\left(\frac{\partial c}{\partial t_{r}} t_{c}+\frac{\partial r}{\partial t_{r}} t_{r}\right)=0
\end{aligned}
$$

where $\lambda$ is the representative household's marginal utility of income.

Define the marginal external damage from a unit of $d$ as $\tau \equiv-\frac{\partial \nu}{\partial D} \cdot \frac{n}{\lambda}>0$, and substitute it into (12a) and (12b). Using the Slutsky equations, ${ }^{14}$ we write the first order conditions in matrix form:

$$
\left[\begin{array}{ll}
s_{c c} & s_{r c} \\
s_{c r} & s_{r r}
\end{array}\right]\left[\begin{array}{l}
t_{c} \\
t_{r}
\end{array}\right]=\left[\begin{array}{c}
\frac{(\lambda-\mu)}{\mu} c+\frac{\lambda \tau}{\mu}\left(s_{d c}-\frac{\partial d}{\partial y} c\right)+c\left(\frac{\partial c}{\partial y} t_{c}+\frac{\partial r}{\partial y} t_{r}\right) \\
\frac{-(\lambda-\mu)}{\mu} r+\frac{\lambda \tau}{\mu}\left(s_{d r}+\frac{\partial d}{\partial y} r\right)-r\left(\frac{\partial c}{\partial y} t_{c}+\frac{\partial r}{\partial y} t_{r}\right)
\end{array}\right]
$$

where $y$ is total household income and $s_{i j}$ is an element of the Slutsky matrix (e.g. $s_{c r}$ is the compensated change in good $c$ for a change in the price of home production, $1-t_{r}$ ). Now use Cramer's rule to obtain expressions for $t_{c}$ and $t_{r}$ :

$$
\begin{aligned}
& t_{c}=\frac{\left(s_{r r} c+s_{r c} r\right)(\gamma-1)}{s_{c c} s_{r r}-s_{c r} s_{r c}}+\frac{\tau}{\mu / \lambda} \cdot \frac{\left(s_{d c} s_{r r}-s_{d r} s_{r c}\right)}{\left(s_{c c} s_{r r}-s_{c r} s_{r c}\right)} \\
& t_{r}=\frac{\left(s_{c c} r+s_{c r} c\right)(1-\gamma)}{s_{c c} s_{r r}-s_{c r} s_{r c}}+\frac{\tau}{\mu / \lambda} \cdot \frac{\left(s_{d r} s_{c c}-s_{d c} s_{c r}\right)}{\left(s_{c c} s_{r r}-s_{c r} s_{r c}\right)}
\end{aligned}
$$

${ }^{13}$ Roy's identity: $\frac{\partial v}{\partial t_{r}}=-\lambda r$ and $\frac{\partial v}{\partial t_{c}}=-\lambda c$, where $\lambda$ is the private marginal utility of income.

${ }^{14}$ In this context, the Slutsky equations are $\frac{\partial j}{\partial t_{i}}=s_{j i}-\frac{\partial j}{\partial y} \cdot i$, where $i=c$ or $d$, and $j=c, d$ or $r$. Also, $\frac{\partial j}{\partial t_{r}}=-s_{j r}-\frac{\partial j}{\partial y} \cdot r$, where $j=c, d$ or $r$ (see Deaton and Muelbauer 1980, p. 45). 
where $\gamma \equiv \frac{1}{\mu / \lambda}-\left[\frac{\tau}{\mu / \lambda} \cdot \frac{\partial d}{\partial y}\right]+\left[\frac{\partial c}{\partial y} \cdot t_{c}+\frac{\partial r}{\partial y} \cdot t_{r}\right]$.

Before we simplify these expressions further, we pause to discuss interpretations of $\mu / \lambda$ and $\gamma$. First, note that $\mu$ is the marginal cost in terms of utility from a dollar of public spending, and it is converted into dollars when divided by the marginal utility of income $\lambda$. Thus, $\mu / \lambda$ is the dollar cost to households of a dollar of public spending (known as the marginal cost of funds, MCF). Second, note that $\gamma$ is a generalization of $\gamma$ in the first model above, the social marginal utility of private income (but here measured in units of public expenditure). ${ }^{15}$

This $\gamma$ includes three effects of private income: on private utility, on the environmental externality, and on tax revenue. The first part of $\gamma$ is the inverse of the marginal cost of funds. This term is positive, and it captures the social costs of taxation. With $\mathrm{MCF}>1$, this first "tax effect" term is less than one. The second part of $\gamma$ is the externality effect described by Schöb (1997), the social external cost $(\tau)$ multiplied by the change in consumption of the dirty good for a change in household income, $\partial d / \partial y$, all divided by the MCF. Assuming $d$ is a normal good, this term also is positive, but its subtraction makes $\gamma$ smaller than it would be in the absence of the externality. The third part of $\gamma$ represents the revenue effect identified by Atkinson and Stern (1974); it captures the change in tax revenue from both tax instruments $\left(t_{c}\right.$ and $t_{r}$ ) as income changes. This component of $\gamma$ has more terms. If the clean good is a normal good, then $\partial c / \partial y$ is positive. Since it is multiplied by $t_{c}$, which we will show is a subsidy, the first portion of the revenue effect is negative. The income effect on household resources supplied to the market, $\partial r / \partial y$, is also negative (assuming leisure or home production is a normal good). This is multiplied by $t_{r}$, which is positive, so the whole third term is a negative revenue effect.

We will return to the general case in (14a) and (14b) but now consider the special case where leisure is separable from $c$ and $d$ and utility is homogeneous. As detailed in the Appendix, we use the symmetry properties of the compensated cross-price effects in the Slutsky equations to simplify the two tax rate expressions:

$$
\begin{aligned}
& \frac{t_{c}}{\left(1+t_{c}\right)}=-\frac{\tau}{\mu / \lambda} \\
& \frac{t_{r}}{\left(1-t_{r}\right)}=\frac{\tau}{\mu / \lambda}+\frac{(1-\gamma)}{\varepsilon}
\end{aligned}
$$

where $\varepsilon=\varepsilon_{c r}=\varepsilon_{d r}$ is the compensated cross-price elasticity of $c$ or $d$ with respect to the price of leisure, $\left(1-t_{r}\right) .^{16}$

Equation (15a) expresses the tax on the clean good as a fraction of the consumer price $\left(1+t_{c}\right)$. It equals the negative of the marginal external damage from a unit of the dirty good, $\tau$, divided by the marginal cost of funds $\mu / \lambda$. Since both $\tau$ and $\mu / \lambda$ are positive, the tax on $c$ is negative. In other words, the government subsidizes private consumption of the clean good $c .{ }^{17}$

\footnotetext{
${ }^{15}$ For further discussion of the MCF, see Stiglitz and Dasgupta (1971) or Atkinson and Stern (1974). For further discussion of the components of $\gamma$, see Diamond (1975) and Schöb (1997).

${ }^{16}$ Because of separability, Appendix equation (A4) shows that $s_{d r} / d=s_{c r} / c$. Thus $\varepsilon_{d r}=\varepsilon_{c r}$.

${ }^{17}$ Bovenberg and van der Ploeg (1994) derive the tax on the polluting good as the MED divided by MCF. Here, we are finding a similar rate with the opposite sign for the subsidy to the clean good,
} 
With lump-sum taxes, the marginal cost of funds $\mu / \lambda$ is equal to one, and the subsidy to the clean good reduces to $-\tau$, where $\tau /-\frac{\partial}{\partial D} \cdot \frac{n}{\lambda}>0$. Equation (15a) then matches the simple first-best case above (see equation $6 b$ ). With distorting taxes, however, a dollar of revenue imposes costs on consumers of more than a dollar. The marginal cost of funds $\mu / \lambda$ is greater than one, and the second-best subsidy to the clean good is smaller than in first-best.

Equation (15b) expresses the tax rate on the household resource, $t_{r}$, as a fraction of the supplier's net return $\left(1-t_{r}\right)$. It consists of two main components: an environmental component that corrects for the negative externality and a revenueraising component. The environmental component is nothing more than the negative of the subsidy to the clean good (and is therefore positive). It is equal to the MED from a unit of the dirty good, divided by the marginal cost of public funds. This term is the "deposit," collected on all income, and it is returned only when the consumer uses that income to buy clean commodities. Together, the deposit on all income and rebate to $c$ are equivalent to a tax on the dirty good. Even the net revenue from this $2 \mathrm{PI}$ is the same as the revenue from the pollution tax. If this revenue is just enough to pay for public spending on $G$, or if lump-sum taxes are available, then no distorting taxes are necessary - which means that the marginal cost of funds $(\mu / \lambda)$ is one, and the revenue-raising component of $t_{r}$ is zero (so $\left.\gamma=1\right)$. Then $t_{r}$ in $(15 \mathrm{~b})$ reduces to $\tau$, which matches the first-best case in equation (6b).

Assuming this net revenue is not enough to pay for all government spending, however, the second component of $t_{r}$ must also be positive. This revenue-raising component is $(1-\gamma) / \varepsilon$, and the separability assumption means that either good $(c$ or $d$ ) is a substitute for leisure, so $\varepsilon$ is positive. Since $\gamma$ is the social marginal utility of income, it must be greater than zero. Thus, in combination, we have $0<\gamma<1$.

In a world with multiple distortions, the government has at least two goals for taxation: to correct for the negative externality and to raise revenue optimally. While the subsidy on the clean good only serves to aid in the correction of an environmental externality, the tax on the household resource helps serve both of these goals. The externality-correcting component of the tax and subsidy is smaller than in the first-best model, due to the marginal cost of funds greater than one, but then the revenue-raising component of $t_{r}$ is larger. In other words, the revenueraising second-best tax rate is larger than in the first-best model.

In our introduction, we note that the logic of revenue raising might be expected to make the deposit larger and the rebate smaller than in the first-best case. Here, we have just shown that the answer to this question depends on one's interpretation of what constitutes "the deposit." If the deposit is all of $t_{r}$ in equation (15b), then indeed the deposit is larger given the need for revenue. And because the MCF $(\mu / \lambda)$ in the denominator of $(15 a)$ is more than one, the rebate is indeed smaller than in the first-best case.

If the "deposit" is defined solely as the first term of the income tax rate, however, then both the deposit and the rebate are smaller than in the first-best case. The logic for this result is that the two-part instrument is equivalent to a tax on pollution. With a labor tax and separability of leisure in utility, Bovenberg and de

paired with a more complicated tax on all resources. Also, as in the first-best model above, the case with many clean goods $c_{i}$ (for $\left.i=1, \ldots, N\right)$ means that all get the same subsidy $\tau / \mathrm{MCF}$, as in $(15 \mathrm{a}$ ). 
Mooij (1994) show that the second-best tax on pollution is less than in the first-best case, so here both the deposit and the rebate are less than in the first-best case.

Finally, we return to the general case where leisure is not separable from $c$ and $d$. Equations (14) do not yield simple closed-form solutions for the two tax rates, but consider what happens to each tax rate in the separable case of equations (15) for a slight deviation from separability. As $c$ becomes less of a substitute for leisure (or even a complement), then $s_{c r}$ becomes smaller (or even negative). Then $s_{r c}=-S_{c r}$ becomes less negative (or even positive), and the first term of $t_{c}$ in (14a) changes from zero to positive. In other words, the subsidy to the clean good acquires a revenue-raising term unrelated to pollution. As in other optimal tax results, the tax is higher on a relative complement to leisure. In this case, the subsidy is smaller. If $s_{r c}$ becomes large enough (or damages $\tau$ small enough), then the subsidy to the clean good may switch to a tax. Also, for the same deviation from separability, as $s_{c r}$ becomes smaller (or even negative), the first term in (14b) becomes smaller. In other words, the revenue-raising term in $t_{r}$ becomes smaller because some of the revenue is raised within $t_{c}$.

\section{Caveats}

In addition to the fact that the taxes and subsidies apply only to market transactions, the two-part instrument has other potential advantages. Whereas the emissions tax may require introducing a new tax instrument, the 2PI may be administered through existing systems. The presumptive tax may be part of the existing excise tax structure or the existing income tax - and thus not separately visible to the taxpayer. The subsidy may appear as a sales tax that is lower on $c$ than on other goods, or as an income tax rate that is lower on clean inputs. Thus, the consumer may not even notice the connection between the tax and the subsidy, despite the fact that together they induce optimal behavior.

On the other hand, the two models above are too simple. Usually, one can think of relevant caveats by listing simplifications in the model: many identical firms using only one or two inputs to produce output in competitive markets with perfect information and no other distortions. In this case, however, many simplifications affect both the Pigovian tax and two-part instrument solutions similarly. Noncompetitive pricing would complicate the two-part instrument, for example, but it also complicates the calculation of an optimal emission tax rate. The problem of measuring marginal external damage is similar for both solutions. Monitoring pollution is a worse problem for the Pigovian tax, of course, but other problems are specific to the two-part instrument.

First, the two-part instrument may not work if the output tax itself is difficult to enforce. Subsistence farmers in developing nations may eat their own output instead of selling it in the market where it could be taxed. Likewise, small firms may avoid government regulation and taxation by participating in the large informal sector that exists in many developing countries. If so, then no solution can be "firstbest," but new research still could think broadly about combinations of instruments to improve welfare. Perhaps only exports can be taxed, for example, if those are the only transactions that generate an invoice. A subsidy to clean inputs and a tax on exports is not first-best, but the use of these two instruments together is likely to perform better than the use of either one alone. 
Second, disaggregation may imply that more tax rates are necessary for the 2PI, which complicates its practical implementation. With many inputs, the tax on output needs to be matched by a subsidy to all clean inputs. Or, with many pollutants, the tax on output needs to reflect the largest MED. The 2PI becomes a multi-part instrument: clean inputs receive back all of that "maximum" deposit, while each remaining dirty input receives a subsidy equal to that deposit minus its own MED. As an example, consider the case of a plant that uses various chemical inputs. It produces an output for sale, materials for recycling, and materials for disposal. The first part of the 2PI is a tax on each chemical input that corresponds to the likely MED from illegal dumping. ${ }^{18}$ Then the second part is a set of rebates. Each unit of output gets a rebate that corresponds to the amount of tax on its chemical content. Each unit of recycling gets a similar subsidy, reduced by the MED from recycling. Each unit of disposal gets a rebate equal to the original tax on its chemical content minus the MED from that type of disposal. Any illegally dumped chemical input does not get a rebate, but it has already paid the social marginal cost up-front.

Third, heterogeneity matters. If all firms have the same MED but different production functions, then the optimal tax on emissions is uniform but the optimal 2PI is not: the optimal subsidy rate for each clean input may depend on the firm using it. Perfect implementation of the 2PI could be complicated and the first-best outcome difficult to attain. If a direct emissions tax is not possible, however, even a uniform subsidy and output tax may be a good option. Yet, since it is not first-best, welfare may be improved by taxes or subsidies on other goods. Similarly, if damages differ, then both the direct tax and 2PI can be improved by taxes or subsidies on good that are related to activities of consumers or firms with high or low damages (as in Diamond, 1973, Green and Sheshinski, 1976, and Balcer, 1980).

Fourth, even though we consider the case where leisure is not separable from the two private goods, we continued to assume that all of those goods are separable from environmental quality (as represented by the aggregate dirty good, $D$ ). Cremer, Gahvari and Ladoux (2001) allow for the non-separability of environmental quality from leisure and find that a direct tax on the dirty good may be either smaller or larger than the Pigovian rate. ${ }^{19}$ This observation is equally applicable to the environmental component of the 2 PI derived above. If environmental quality and leisure are substitutes, then the social planner would increase the effective tax rate on the dirty good. As individuals decrease their consumption of $d$, then environmental quality improves, and individuals substitute out of leisure. The increase in working hours helps to mute the distortion introduced by the labor tax. Conversely, if environmental quality and leisure are complements, then the effective tax rate on the dirty good should be smaller than shown in (15a) and (15b).

Fifth, marginal environmental damage may vary by time of day, season of the year, or location. The emissions tax may be varied in this fashion, if it is available at all, but the 2PI includes a tax on output that could not be matched to the time or place of emissions. Ozone is an example of a pollutant that varies by time of day and season, which optimally would require time-specific emission tax rates.

Sixth, not all subsidies reduce cost and encourage output in ways that require an output tax. A different kind of subsidy may be paid directly for reductions in

\footnotetext{
${ }^{18}$ Strictly speaking, the total tax on the firm may be a function of the inputs, corresponding to the damage from dumping the worst possible chemical combination of those inputs.

${ }^{19}$ Another paper that explores the implications of separability is Cremer and Gahvari (2001).
} 
pollution, which raises the opportunity cost of pollution and production. It may provide rents to those paid for reductions, but it raises the price of output and has allocation effects that match the Pigovian tax (Baumol and Oates, 1988). The crucial feature of subsidies considered in this paper is that they reduce costs by applying to inputs other than the damaging activity. See Parry (1998) for a discussion of subsidy types and examples of each.

Seventh, as any economy develops and technology changes, the best policy also is likely to change. For example, brick-makers in Mexico often fire their ovens using dirty fuels such as used tires or motor oil. These many small family-run operations are impossible to monitor (Blackman and Bannister, 1998). A 2PI may tax output and subsidize propane use, but even the tax on output would be hard to enforce because of informal markets. As the economy and brick market develop, a tax on bricks may become part of a two-part instrument. Then, as technology further develops, the 2PI may eventually be replaced by an optimal emissions tax (or permit trading). Even in the U.S., the availability of CEM technology made possible the recent Clear Skies legislation proposing a cap-and-trade program for sulfur dioxide, nitrous oxide, and mercury emissions from large electric utilities. ${ }^{20}$

Finally, several other complications require further research. Trade across jurisdictions could mean that the deposit needs to be refunded on exports and collected on imports. Trade in waste is a particular illustration of this problem. Indeed, if the subsidy to clean disposal of waste is high enough, it may induce some to steal waste from others or to create waste! Thus, the 2PI may work best where the subsidy is implicit, as through free pick-up of curbside garbage and recycling, intended to curtail dumping elsewhere. Also, the two-part instrument may not always replicate the effect of the emissions tax (such as without constant returns to scale or a profits tax). Still, the advisability of the 2PI depends on the alternatives. If an emissions tax is easily imposed, then that is bound to be a good solution. If not, then the tax-subsidy combination is likely to dominate any one instrument alone.

\section{Conclusion}

We have demonstrated that the combination of a tax on household income and a subsidy to consumption of the clean good is equivalent to the combination of a revenue-raising tax on income and additional tax on pollution. Both systems also are equivalent to commodity taxes with a higher rate on the dirty good. In the event that policymakers cannot tax the dirty good, even though it is causing a negative externality, they can still find a combination of tax rates on the two remaining goods in the economy that correct for the externality and raise revenue for the government.

In the model where distortionary taxes are necessary to meet a revenueraising requirement, the negative externality factors into the second-best tax rates in two ways. First, the subsidy to the clean good and a portion of the income tax together correct for the negative externality. Second, the environmental externality changes the portion of the income tax that raises revenue, because the marginal external damage affects the social marginal utility of income. The revenue-raising

\footnotetext{
${ }^{20}$ One important topic for future research is to compare the incentives for R\&D. While the emissions tax provides incentives for the invention of cleaner technologies over time, a subsidy cannot be provided for technologies not yet invented. The 2PI may provide comparable incentives only if firms assume that new technologies will receive subsidies at appropriate rates.
} 
requirement implies that the subsidy is smaller than in the first-best model. The externality-correcting component of the tax rate is also smaller than in the first-best model. The revenue component is zero in the first-best model but becomes positive in the second-best model. Overall, due to this component, the second-best tax rate is larger than in the first-best model.

A tax-subsidy combination, with or without a revenue-raising requirement, is a flexible incentive-based instrument. The two parts of the instrument do not have to apply to the same economic agent, and do not necessarily apply at the same rate or even to the same commodity. Several interpretations demonstrate how the revenueraising two-part instrument is useful for addressing a number of pollution problems. We note, however, that the two-part instrument is not appropriate in every context, and we discuss some of the main caveats that should be kept in mind when considering its applicability. 


\section{Appendix: Derivation of Second-Best Tax Rates}

To simplify equations (14a) and (14b), we use the separability and homogeneity assumptions. We begin with equation (14a), the expression for $t_{c}$. Homogeneity in utility implies that $\sum_{k} s_{i k} p_{k}=0$. The relationships we use are:

$$
\begin{aligned}
& s_{h h}\left(1-t_{r}\right)+s_{h c}\left(1+t_{c}\right)+s_{h d}=0 \Leftrightarrow s_{r r}\left(1-t_{r}\right)+s_{r c}\left(1+t_{c}\right)+s_{r d}=0, \\
& s_{c h}\left(1-t_{r}\right)+s_{c c}\left(1+t_{c}\right)+s_{c d}=0 \Leftrightarrow s_{c r}\left(1-t_{r}\right)+s_{c c}\left(1+t_{c}\right)+s_{c d}=0 .
\end{aligned}
$$

Using (A1) we now rewrite $s_{r r} c+s_{r c} r$ as:

$$
c\left[\frac{-s_{r c}\left(1+t_{c}\right)-s_{r d}}{1-t_{r}}\right]+s_{r c} r
$$

From Goldman and Uzawa (1964) and Sandmo (1974), separability implies that $s_{h c}=\beta h c$ and $s_{h d}=\beta h d$ where $\beta$ is a function of arguments in the utility function. We also know that $s_{d h}=s_{h d}=s_{d r}=-s_{r d}$. Using these relationships, we find:

$$
-S_{r d}=s_{d r}=s_{c r} \cdot d / c
$$

Symmetry properties of the substitution matrix also tell us that $S_{c r}=-S_{r c}$. Using symmetry, we substitute (A4) into (A3) so that:

$$
s_{r r} c+s_{r c} r=\left(\frac{1}{\left(1-t_{r}\right)}\right)\left(-s_{r c} c\left(1+t_{c}\right)-s_{r c} d+s_{r c} r\left(1-t_{r}\right)\right)
$$

Factoring out $s_{r c}$ on the right hand side and using the household budget constraint, $\left(1+t_{c}\right) c+d=\left(1-t_{r}\right) r$, shows that (A5) is equal to zero. Thus, the expression for $t_{c}$ in (14a) becomes:

$$
t_{c}=\frac{\lambda \tau}{\mu} \cdot \frac{\left(s_{d c} s_{r r}-s_{d r} s_{r c}\right)}{\left(s_{c c} s_{r r}-s_{c r} s_{r c}\right)} .
$$

To further simplify, we examine the denominator $\left(s_{c c} s_{r r}-s_{c r} s_{r c}\right)$. To begin, we use (A2) to get:

$$
s_{c c} s_{r r}-s_{c r} s_{r c}=\left[\frac{-s_{c r}\left(1-t_{r}\right)-s_{c d}}{\left(1+t_{c}\right)}\right]\left[\frac{-s_{r c}\left(1+t_{c}\right)-s_{r d}}{\left(1-t_{r}\right)}\right]+s_{c r} s_{r c} .
$$

Again, we use the symmetry properties $s_{c r}=-s_{r c}$ and $s_{d r}=-s_{r d}$ as well as (A4), the separability result. Then (A7) becomes:

$$
s_{c c} s_{r r}-s_{c r} s_{r c}=\left[-\frac{\left(1-t_{r}\right)}{\left(1+t_{c}\right)} s_{c r}-\frac{1}{\left(1+t_{c}\right)} s_{c d}\right]\left[\frac{\left(1+t_{c}\right) c+d}{\left(1-t_{r}\right) c} s_{c r}\right]+s_{c r}^{2} .
$$


Substituting in the household budget constraint, we obtain:

$$
\begin{array}{r}
s_{c c} s_{r r}-s_{c r} S_{r c}=\left[-\frac{\left(1-t_{r}\right)}{\left(1+t_{c}\right)} s_{c r}-\frac{1}{\left(1+t_{c}\right)} S_{c d}\right]\left[\frac{r}{c} s_{c r}\right]+s_{c r}^{2} \\
=-\frac{\left(1-t_{r}\right) r}{\left(1+t_{c}\right) c} s_{c r}^{2}+\frac{\left(1+t_{c}\right) c}{\left(1+t_{c}\right) c} s_{c r}^{2}-\frac{r}{\left(1+t_{c}\right) c} S_{c d} S_{c r} .
\end{array}
$$

We simplify further by again using the household budget constraint:

$$
s_{c c} s_{r r}-s_{c r} s_{r c}=\left(d s_{c r}+r s_{c d}\right) \frac{-s_{c r}}{\left(1+t_{c}\right) c} .
$$

We now examine the numerator $\left(s_{d c} s_{r r}-s_{d r} s_{r c}\right)$. Substitute in (A1) and the symmetry conditions from the substitution matrix:

$$
s_{d c} s_{r r}-s_{d r} s_{r c}=\frac{s_{c d} s_{d r}}{\left(1-t_{r}\right)}+\frac{s_{c d} s_{c r}\left(1+t_{c}\right)}{\left(1-t_{r}\right)}+s_{d r} s_{c r}
$$

Now substitute (A4), the separability result, into (A11) to get:

$$
s_{d c} s_{r r}-s_{d r} s_{r c}=\frac{1}{\left(1-t_{r}\right) c}\left[s_{c d} s_{c r}\left(d+c \cdot\left(1+t_{c}\right)\right)+s_{c r}^{2} d\left(1-t_{r}\right)\right] .
$$

Using the household budget constraint, (A12) is further simplified:

$$
\begin{gathered}
s_{d c} s_{r r}-s_{d r} s_{r c}=\frac{1}{\left(1-t_{r}\right) c}\left[s_{c d} s_{c r} r\left(1-t_{r}\right)+s_{c r}^{2} d\left(1-t_{r}\right)\right] \\
=\frac{s_{r c}}{c}\left(s_{c d} r+s_{c r} d\right) .
\end{gathered}
$$

When we plug (A10) and (A13) into (A6), we obtain a much simpler expression for $t_{c}$, equation (15a) in the text.

We perform a similar simplification process for the expression for $t_{r}$, equation $(14 b)$ in the text. The denominator is the same as that in (A6); the simplified form is (A10). The numerator also is simplified. We will begin by examining $s_{c c} r+s_{c r} c$. Using (A2), the homogeneity assumption, we obtain:

$$
\frac{-1}{\left(1+t_{c}\right)}\left[s_{c r} r\left(1-t_{r}\right)+r s_{c d}-s_{c r} c\left(1+t_{c}\right)\right]
$$

Again, the household budget constraint is useful; we simplify (A14) to: 


$$
s_{c c} r+s_{c r} c=\frac{-1}{\left(1+t_{c}\right)}\left(d s_{c r}+r s_{c d}\right)
$$

We also simplify $s_{d r} s_{c c}-s_{d c} s_{c r}$. Substitute in (A2), the homogeneity of demand assumption, as well as several symmetry conditions to obtain:

$$
s_{d r} S_{c c}-s_{d c} s_{c r}=\frac{1}{\left(1+t_{c}\right)}\left[-s_{d r} s_{c r}\left(1-t_{r}\right)-s_{c d} s_{c r}\left(1+t_{c}\right)-s_{c d} s_{d r}\right] .
$$

Now substitute (A4), the separability condition, into (A14) to obtain:

$$
s_{d r} S_{c c}-s_{d c} S_{c r}=\frac{-S_{c r}}{\left(1+t_{c}\right) c}\left[s_{c r} d\left(1-t_{r}\right)+s_{c d}\left(d+c\left(1+t_{c}\right)\right)\right]
$$

We simplify this expression even further by using the household budget constraint:

$$
s_{d r} s_{c c}-s_{d c} s_{c r}=\frac{-s_{c r}\left(1-t_{r}\right)}{\left(1+t_{c}\right) c}\left[s_{c r} d+s_{c d} r\right]
$$

Substitute (A10), (A15) and (A18) into equation (14b) from the text to get:

$$
\frac{t_{r}}{\left(1-t_{r}\right)}=\frac{\tau}{\mu / \lambda}+\frac{c}{s_{c r}} \cdot \frac{(1-\gamma)}{\left(1-t_{r}\right)}
$$

Finally, note that $s_{c r}\left(1-t_{r}\right) / c$ is the elasticity $\varepsilon_{c r}$, and we obtain $(15 \mathrm{~b})$ in the text. 


\section{References}

Atkinson, A. and N. Stern (1974). "Pigou, Taxation and Public Goods." Review of Economic Studies 41, January, 119-128.

Auerbach, A. (1985). "Excess Burden and Optimal Taxation" in A. Auerbach and M. Feldstein (eds.), Handbook of Public Economics. Vol. I. Amsterdam: North Holland, 61-127.

Balcer, Y. (1980). "Taxation of Externalities: Direct Versus Indirect." Journal of Public Economics 13, 121-129.

Ballard, C. L., J. H. Goddeeris, and S. K. Kim (2000). "Non-homothetic Preferences and the Double Dividend." Working Paper, Michigan State University.

Baumol, W. and W. Oates (1988). The Theory of Environmental Policy. Second Edition. New York: Cambridge University Press.

Blackman, A. and G. Bannister (1998). "Community Pressure and Clean Technology in the Informal Sector: An Econometric Analysis of the Adoption of Propane by Traditional Mexican Brickmakers." Journal of Environmental Economics and Management 35(1), January, 1-21.

Bovenberg, A. L. and R. de Mooij (1994). "Environmental Levies and Distortionary Taxation." American Economic Review 84(4), September, 1085-1089.

Bovenberg, A. L. and L. Goulder (1996). "Optimal Environmental Taxation in the Presence of Other Taxes: General-Equilibrium Analyses." American Economic Review 86(4), September, 985-1000.

Bovenberg, A. L. and F. van der Ploeg (1994). "Environmental Policy, Public Finance and the Labor Market in a Second-Best World." Journal of Public Economics 55(3), November, 349-390.

Cohen, M. (1999). "Monitoring and Enforcement of Environmental Policy." In T. Tietenberg and H. Folmer (eds.), International Yearbook of Environmental and Resource Economics 1999/2000, Cheltenham, UK: Edward Elgar.

Cremer, H., and F. Gahvari (2001). "Second-Best Taxation of Emissions and Polluting Goods.” Journal of Public Economics 80, 169-197.

Cremer, H., F. Gahvari, and N. Ladoux (2001). "Second-Best Pollution Taxes and the Structure of Preferences." Southern Economic Journal 68(2), 258-280.

Deaton, A. and J. Muellbauer (1980). Economics and Consumer Behavior. New York: Cambridge University Press.

Diamond, P. (1973). "Consumption Externalities and Imperfect Corrective Pricing." Bell Journal of Economics and Management Science 4, 526-538. 
Diamond P. (1975). "A Many-Person Ramsey Tax Rule." Journal of Public Economics 4(4), November, 335-342.

Eskeland, G. (1994). "A Presumptive Pigovian Tax: Complementing Regulation to Mimic an Emissions Fee." The World Bank Economic Review. Washington, DC: World Bank.

Eskeland, G. and S. Devarajan (1996). Taxing Bads by Taxing Goods: Pollution Control with Presumptive Charges. Washington, DC: World Bank.

Fullerton, D. (1997). "Environmental Levies and Distortionary Taxation: Comment." American Economic Review 87(1), March, 245-251.

Fullerton, D. and S. West (2002). "Can Taxes on Cars and on Gasoline Mimic an Unavailable Tax on Emissions?" Journal of Environmental Economics and Management 43(1), January, 135-157.

Fullerton, D. and A. Wolverton (1999). "The Case for a Two-Part Instrument: Presumptive Tax and Environmental Subsidy" in A. Panagariya, P. Portney, and R. Schwab (eds.), Environmental and Public Economics: Essays in Honor of Wallace E. Oates. Cheltenham, UK: Edward Elgar.

Goldman, S. and H. Uzawa (1964). "A Note on Separability in Demand Analysis." Econometrica 32(3), July, 387-398.

Green, J. and E. Sheshinski (1976). "Direct versus Indirect Taxation of Externalities." The Journal of Political Economy 84(4), 797-808.

Harrington, W. (1988). "Enforcement Leverage When Penalties Are Restricted." Journal of Public Economics 45(3), 391-395.

Kim, S. R. (2002). "Optimal Environmental Regulation in the Presence of Other Taxes: The Role of Non-separable Preferences and Technology." Contributions to Economic Analysis \& Policy 1(1), article 4.

Lear, K. (1998). "An Empirical Estimation of EPA Administrative Penalties." Working Paper, Kelley School of Business, Indiana University.

Magat, W. and K. Viscusi (1990). "Effectiveness of the EPA's Regulatory Enforcement: The Case of Industrial Effluent Standards." Journal of Law and Economics 33, 331-360.

Palmer, K. and M. Walls (1997). "Optimal Policies for Solid Waste Disposal: Taxes, Subsidies, and Standards." Journal of Public Economics 65(2), August, 193205.

Parry, I. W. H. (1995). "Pollution Taxes and Revenue Recycling." Journal of Environmental Economics and Management 29(3), November, S64-S77. 
Parry, I. W. H. (1998). "A Second-Best Analysis of Environmental Subsidies." International Tax and Public Finance 5(2), 153-170.

Pigou, A. (1920). The Economics of Welfare. London: MacMillan.

Russell, C., W. Harrington, and W. Vaughn (1986). Enforcing Effective Pollution Control. Washington, DC: Resources for the Future.

Sandmo, A. (1974). "A Note on the Structure of Optimal Taxation." American Economic Review 64(4), 701-706.

Sandmo, A. (1975). "Optimal Taxation in the Presence of Externalities." Swedish Journal of Economics 77(1), March, 86-98.

Sandmo, A. (1976). "Direct Versus Indirect Pigovian Taxation." European Economic Review 7, 337-349.

Schöb, R. (1997). "Environmental Taxes and Pre-Existing Distortions: The Normalization Trap." International Tax and Public Finance 4(2), May, 167-176.

Stiglitz, J. and P. Dasgupta (1971). "Differential Taxation, Public Goods, and Economic Efficiency." Review of Economic Studies 38(2), April, 151-174.

U.S. General Accounting Office (1990). Improvements Needed in Detecting and Preventing Violations. Washington, DC: US GAO.

West, S. and R. Williams (2002). "Empirical Estimates for Environmental Policy Making in a Second-Best Setting." Working Paper, University of Texas.

Walls M. and K. Palmer (2001). "Upstream Pollution, Downstream Waste Disposal, and the Design of Comprehensive Environmental Policies." Journal of Environmental Economics and Management 41(1), January, 94-108. 